\title{
La escritura como téchne del cuerpo (acotaciones históricas y evolución)
}

Juan Carlos Valdés Godines*

\section{Resumen}

El trabajo presentado es un ensayo que establece la relación entre las categorías tecnología-cuerpo-escritura y la forma en que los cambios en la tecnología (digital) transforman las relaciones entre ellas. El objetivo consiste en construir referentes teóricos que permitan a la pedagogía contemporánea plantear y explorar procesos educativos alternativos surgidos a partir de los usos de la tecnología digital. El método utilizado es principalmente el reflexivo-analítico que permite el establecimiento de relaciones entre las categorías para realizar construcciones y deconstrucciones de planteamientos pedagógicos tradicionales; el trabajo representa una propuesta de como realizar análisis deconstructivos de categorías pedagógicas tradicionales para comprender su surgimiento, evolución y posibilidades a partir de la diversidad de prácticas educativas con las tecnologías digitales.

Palabras clave: tecnología digital; escritura; téchne; racionalidad tecnológica; cuerpo.

\section{Writing as techne of the body: historical notes and evolution}

\section{Abstract}

The work presented is an essay that establishes the relationship between the technology-body-writing categories and the way in which changes in technology (digital) transform the relationships between them. The objective is to build theoretical references that allow contemporary pedagogy to raise and explore alternative educational processes arising from the uses of digital technology. The method used is mainly the reflexive-analytical one that allows the establishment of relationships between the categories

* Dr. en pedagogía 
to carry out constructions and deconstructions of traditional pedagogical approaches; the work represents a proposal of how to perform deconstructive analyzes of traditional pedagogical categories to understand their emergence, evolution and possibilities from the diversity of educational practices with digital technologies.

Keywords: digital technology; writing; téchne; technological rationality; body.

\section{Introducción}

El presente trabajo es un ejercicio de reconstrucción conceptual, una especie de restauración en la cual se reconstruye la relación existente entre los conceptos de escritura, tecnología y cuerpo, que parecieran no tener implicaciones entre sí y que sin embargo, para el abordaje de los fenómenos que se exponen, existe un entramado interesante de analizar que ha evolucionado de acuerdo con la actual dinámica socio-cultural, tecnológica y la relación de ello con la educación.

\section{Algunas ideas iniciales acerca de la tecnología}

De inicio o la manera de ejercicio deconstructivo se replantea el concepto de tecnología, que tal vez es lo que aparece como lo más desconectado en relación a la escritura y el cuerpo; cuando se hace referencia a la tecnología regularmente se piensa en instrumentos, herramientas, y aparatos electrónicos básicamente; en términos generales nos remitimos a las "cosas externas" a nuestro cuerpo que nos permiten realizar infinidad de actividades cotidianas y en ese sentido, facilitan nuestra existencia en el mundo.

Existe también la idea protésica instrumental de la tecnología, es decir, entender a los aparatos tecnológicos como extensiones instrumentales de nuestra estructura corporal, sin embargo, la compleja evolución de los instrumentos tecnológicos va más allá de esta idea, como lo señala el autor "La técnica no es lo que el hombre hace para satisfacer sus necesidades. Esta expresión es equívoca y válida también para el repertorio biológico de los actos animales. La técnica es la reforma de la naturaleza, de esa naturaleza que nos hace necesitados y menesterosos, reforma en sentido tal que las necesidades quedan, a ser posible anuladas por dejar de 
ser problema su satisfacción” (ORTEGA Y GASSET, 1965, p. 22), ampliar la idea de la tecnología posibilita un entendimiento más amplio de lo que ésta es, lo cual permite, para los fines de esta exposición, entender a la escritura desde una perspectiva tecnológica, como técnica conectada a los aspectos socio-culturales, cognitivos y fisiológicos.

Es importante tener en cuenta que el uso de las tecnologías genera también dinámicas sociales y culturales incluso el desarrollo de habilidades cognitivas, y de razonamiento, cabe señalar que tanto la idea protésica de la tecnología como la que se refiere a la aplicación tecnológica del conocimiento científico, en su momento explicaron la idea de lo que es la tecnología pero ahora son insuficientes para ello, entre otras razones debido a la dinámica socio-cultural-cognitiva que generan tales instrumentos.

Actualmente la mayor dinámica de investigación, aplicación y desarrollo de la tecnología se presenta en las áreas: industrial, productiva y empresarial fenómeno que inicia sobre todo durante la Revolución Industrial y alcanza su punto álgido en el contexto de la posguerra y del capitalismo posindustrial para lo cual el motor que genera esta dinámica es el conocimiento, más aún, el conocimiento aplicado (base de la moderna tecnociencia) por lo cual la generación, distribución y control del mismo se vuelve determinante para las sociedades contemporáneas.

\section{Repensar la idea de la tecnología en el contexto actual}

En el contexto actual los procesos de surgimiento, generación y reproducción de la tecnología tienen una dinámica muy diferente a la que se venía dando respecto al referente más inmediato como lo es la tecnología industrial, las tecnologías digitales poseen características propias que las han convertido en instrumentos generadores de dinámicas socio-culturales-cognitivas particulares, por ejemplo, el simple hecho de poseer una parte mecánica (tangible) y otra lógica-operativa (intangible), que puedan generar procesos de digitalización de la información así como de imágenes, capaces de crear una realidad virtual y que puedan procesar información a las velocidades neuronales, hacen que estas herramientas sean diferentes cualitativa y cuantitativamente aquéllas de la Revolución Industrial. 
Las tecnologías digitales han creado un lenguaje y código digitales que tienen un gran impacto a nivel sociocultural, al grado en que hoy hablamos de una cultura digital, propia del llamado ciberespacio. Respecto al uso de estas herramientas, no es necesario asistir a algún centro de enseñanza o capacitación, pues generan sus propios espacios de acceso en la vida cotidiana, en la red del Internet a través de las llamadas comunidades virtuales, de tal manera que las tecnologías digitales han creado todo un fenómeno contracultural en su propio espacio antropológico, (el denominado ciberespacio) lo cual ha trastocado las concepciones de aspectos fundamentales sobre los cuales los hombres habíamos construido nuestras certezas básicas como son las ideas del tiempo, espacio y cuerpo (identidad).

A nivel cognitivo estas repercusiones también se han presentado, el surgimiento del código binario y el lenguaje digital (por ejemplo) propician formas alternativas de procesar la información y en consecuencia, formas alternativas de interpretar la realidad actual, la Realidad Virtual (RV) nos ha permitido accesar a otros aspectos de la realidad y entenderlos de diferentes maneras, lo cual representa en gran medida un cambio en los referentes humanos de intelección. Estos impactos profundos de la tecnología digital requieren hacer replanteamientos más amplios de la tecnología, analizar sus dinámicas cognitivas y socio-culturales desde perspectivas filosóficas antropológicas y epistemológicas (entre otras).

Tenemos así que la tecnología no es solamente una linealidad simple de aplicación científica, también implica una serie de actitudes y actividades socio-culturales que constituyen una forma de ver el mundo y enfrentarlo transformándolo de manera recíproca mediante procesos de razonamiento y aplicación de acciones concretas, de esta manera, la esencia de la tecnología no se encuentra ni en la manufactura industrial (que es una invención para la producción en masa) ni en los productos (que son utilizados por los consumidores), sino en el acto de la creación técnica “[...] ésta tiene lugar en armonía con las leyes de la naturaleza a instancias de los propósitos humanos, éstos solo son condición necesaria pero no suficiente para su existencia. Todavía hay algo más, lo que Desauer llama "elaboración" que une la mente del inventor con un "cuarto reino" de las soluciones preestablecidas para resolver problemas técnicos. [...]" (MITCHAM, 1989, p. 47). 
La invención como artefacto tecnológico no existe en el mundo fenomenológico, el hombre no solamente fabrica las cosas como autómata (homo faber), sino que las piensa, razona lo que hace, inventa y crea en tanto homo sapiens, tanto lo hacer como lo pensar conforman la base del proceso de humanización y no se encuentran separados, ni la tecnología genera dicha separación, la tecnología en tanto propicia la invención y creación del mundo que es pensado, de lo que se concibe, funciona como catalizador del simbólico, de las representaciones de la realidad que conforman la cultura, lo cual significa un mayor grado de humanización.

\section{Una idea de apoyo: "La racionalidad tecnológica"}

La racionalidad tecnológica es parte del proceso universal del razonamiento humano, se encuentra estrechamente relacionada con los objetos tecnológicos así como con la creación, utilización y reproducción de los mismos, pero no se remite únicamente a alguno de estos aspectos. El pensamiento, la técnica y la actitud contextualizados por una realidad socio-cultural conforman esta racionalidad tecnológica inmanente en tanto necesaria al proceso de humanización del hombre, que humaniza también al universo que le rodea, en gran medida debido a esta racionalidad tecnológica la cual es propia y diferente de acuerdo a cada contexto socio-cultural y en consecuencia a los objetos tecnológicos característicos de tales contextos.

En gran medida la observación y razonamiento del mundo están determinados por los objetos a través de los cuales observamos y pensamos lo mismo; el fuego, el libro, el auto, la electricidad, etc. cambiaron nuestras formas de ver y pensar el mundo, así como de representarlo, de esta manera la tecnología no es solamente el instrumental, como señala Mitcham (1989, p. 69) al respecto [...] la moderna tecnología no debe ser concebida simplemente como el alivio de la condición humana (Francis Bacon) ella es, además una participación en la creación [...].

La creación y utilización (que no son el todo del proceso de la tecnología) de los objetos tecnológicos poseen implicaciones éticas, morales, estéticas, teológicas, etc. las cuales tienen que ver con la esfera cultural de los seres humanos, de ello se deriva que a estos objetos se les llame objetos tecno-culturales, los cuales "generan lógicas de percepción, que continúan 
su actividad, independientemente de que los poseamos o portemos con nosotros. El mapa organiza nuestra aprehensión del territorio así no lo llevemos con nosotros." (MARÍN ARDILA, 2002, p. 16).

Los objetos tecno-culturales han generado contextos socio-culturales característicos de cada contexto sociocultural al largo de nuestra historia, el libro generó una revolución cultural y cognitiva al igual que la radio, es decir lo que puede señalarse como la estructura contextual de una racionalidad tecnológica.

\section{Otra idea ordenadora: "la téchne"}

La idea griega de la téchne aparece como una virtud, más que como una habilidad o serie de habilidades y mucho menos es entendida solamente como herramientas y/o productos tecnológicos; para entender un poco mejor esta idea es necesario recurrir a la forma mítica de la explicación, tradicional entre los griegos. Al inicio de la creación el hombre aparece en el universo como una criatura más, expuesta a los caprichos de la naturaleza y de los dioses, no posee voluntad alguna, iniciativa, libre albedrío y mucho menos capacidad de incidir o transformar el universo en lo que le tocó vivir, es una "hoja al viento".

El contexto de este hombre es la physis, es decir, la naturaleza de la cual forma parte pero nada más, el mito de Prometeo representa el atrevimiento del hombre que al robar el fuego trata de hacerse de un elemento que a la manera de herramienta le permita liberarse de la voluntad y capricho de los dioses y además poder transformar la physis e incidir en ella adecuándola a sus necesidades e ideas; los primeros hombres que pudieron hacer esto fueron los artesanos que también aprendieron y robaron conocimientos a los dioses, fue entonces el arte lo que permitió al hombre incidir en la physis, plasmar sus ideas propias, por ello el término téchne en sus orígenes tiene mucho que ver con el arte y no sólo con el uso de los objetos tecnológicos; de esta manera el arte y la téchne permiten al hombre separarse de la voluntad divina de los dioses y transformar a la naturaleza.

El significado del saber técnico era diferente al de nuestros días, arte y téchne son los motores del naciente sistema científico, y estos tres aspectos (arte, téchne y ciencia) se encuentran amalgamados con la única 
finalidad de descifrar y comprender la physis; la téchne es lo saber humano que intenta ver lo que los dioses ven plenamente, funda su "saber hacer" en esta visión limitada de las ideas y aparece como una virtud cuando contribuye al buen vivir de los ciudadanos.

No deben confundirse la técnica y la téchne, pues mientras la primera únicamente busca la producción de un objeto útil, la segunda busca un acto perfecto que contribuya a una vida éticamente buena y políticamente justa. La téchne humana se acerca a la physis a la manera de imitación, así entonces el hombre empieza por imitar lo proceder del universo para entenderlo y comprenderlo mejor, este saber humano en su inteligibilidad del universo produce artefactos que representan formas de la inteligencia misma y reproducen también (a manera de modelos) el comportamiento de esa parte del universo que se intenta comprender y explicar, estos artefactos son también la proyección de la intuición e imaginación como formas de la psyche (alma). Este proceso requiere de símbolos, lenguajes, instrumentos, métodos, técnicas, etc.; de tal manera que la téchne es una aplicación deliberada de la inteligencia humana hacia alguna parte del universo, lo cual proporciona al hombre cierta explicación de él mismo brindándole una mejor satisfacción de sus necesidades y la disminución contingente del caos.

Así entonces la idea de téchne implica virtud y razón lo cual nos lleva a entender a la tecnología como una condición necesaria para el desarrollo y progreso de las naciones pero insuficiente para el pleno desarrollo humano.

En este proceso de imitar y comprender el caos del universo para aprehenderlo el hombre ha inventado diversas maneras de representarlo, transformándolo en símbolos que permitan una mejor aprehensión del mismo para lo cual la téchne ha sido fundamental, desde la creación de pigmentos, tintas, materiales de impresión, instrumentos para pintar e imprimir, etc. ha existido la presencia no sólo del artefacto como instrumento tecnológico, sino también, y sobre todo, de esa racionalidad tecnológica que se desarrolla al ponerse en contacto el universo y el hombre que lo aprehende por medio de sus instrumentos de representación que hacen las veces de filtros de inteligibilidad pues dichos instrumentos no son fríos en tanto no actúan por ellos mismos. No existe un animismo que haga mover 
a los artefactos por si solos, dependen de toda una dinámica cognitiva, social y cultural.

\section{La téchne y el mundo representacional escritu- ro-céntrico}

Los objetos al permitirnos dar razón del universo de una determinada manera, influyen en nuestra inteligibilidad del universo mismo; pues su uso implica toda una serie de saberes, habilidades, ritos, mitos, etc. conformando una dinámica socio-cultural más allá de los meros usos prácticos, una racionalidad tecnológica, con todas sus implicaciones históricas que desde siempre han existido.

Para ONG (1987) la escritura es la más trascendental de todas las invenciones tecnológicas humanas, es mucho más que solamente un apéndice del habla. Puesto que traslada el mundo oral y auditivo a un nuevo mundo sensorial, de la vista, transforma el habla y también el pensamiento; lo mismo autor concibe al alfabeto como un reductor despiadadamente eficaz del sonido al espacio, por lo cual representa un cambio en la conciencia humana ya que transforma tanto el pensamiento humano como su forma de expresión.

Es cierto que la escritura es una tecnología pero más allá de esta idea, puede considerarse como téchne pues no solamente es un instrumento tecnológico sino que constituye una forma de racionalidad e inteligibilidad, es decir, conformó y conforma un complejo escenario de inteligibilidad universal, una episteme y en tanto téchne es una virtud de la inteligencia humana que nos permite develar y entender el caos del universo en lo cual vivimos, considerar a la escritura como téchne de nuestro cuerpo permite entenderla como nuestra principal herramienta que posibilita al hombre no sólo pausar simbólicamente el complejo movimiento caótico del universo de lo cual forma parte, al permitirle dar razón del mismo, escribiéndolo y describiéndolo; sino también la escritura permite a nuestro cuerpo expresarse, decir como se siente, como percibe, como cree que son las cosas, se convierte en una extensión de nuestras propiedades y facultades físicas y cognitivas para aprehender el mundo. 
La escritura implica también el movimiento físico de toda nuestra estructura fisiológica, aprender a escribir significa enseñar a nuestro cuerpo a realizar ciertas funciones, así nuestro desarrollo motor es guiado de la torpeza a la precisión requerida para tomar un lápiz y aprender a escribir, nuestros ojos también deben aprender a seguir el movimiento de la mano que realiza los trazos que poco a poco serán más precisos, hasta que logremos adquirir el arte de escribir, recordemos que la téchne implica un arte y una virtud.

De esta manera la escritura se convirtió en una de las funciones básicas de la escuela moderna (la otra es la lectura), de hecho la función escrituro-céntrica fue la razón de ser de la escuela y además influyó en asignarle a los mismos espacios para la acción escolar; una distribución de tiempos y tareas que educan la mente y el cuerpo, que enseñan al cuerpo a leer y escribir, esta dinámica se convertiría en parte esencial del naciente orden institucional característico de la modernidad.

\section{La téchne del cuerpo}

"El cuerpo es una producción humana impensable sin la palabra, la palabra es inasible sin cuerpo, sin cuerpos. Existe una acción humana que literalmente une el cuerpo y la palabra: la escritura" (CRAGNOLINI, 2000 , p. 15). La forma hablada de las palabras fue la primera forma de asir al universo, de darle una explicación pero esa explicación es efímera, momentánea, no es perdurable lo cual será posible hasta que pueda plasmar imágenes de sí mismo.

$\mathrm{Al}$ empezar a nombrar las cosas que le rodean, el hombre lo hace por medio de analogías de acuerdo a semejanzas con otras cosas, como señala Foucault (2007) en su libro Las palabras y las cosas, "El lenguaje vale como signo de las cosas", el universo aparece como un gran texto que puede descifrarse, las explicaciones míticas y fantásticas surgen como recurso para hacer esto, pero este tipo de explicaciones no fueron suficientes para ordenar el universo, el hombre seguía apareciendo como un componente más del caos universal.

Las formas míticas y comparativas de explicación dieron paso al Logos, una forma más razonada de explicar la complejidad del universo y 
aúnque sigue siendo una forma hablada de comunicación, permite sustituir la cultura mítica por una racional, a partir de formas de razonamiento que además ahora permiten reflexionar y dar razón del sujeto como ser pensante, como cuerpo que crea, piensa y siente, deja de ser una criatura más y puede tener una mejor aprehensión del universo.

Sin embargo aún con el surgimiento del Logos derivado de la palabra la forma de comunicación continuó siendo fonética. En este momento el cuerpo es un ente que habla pero que no deja huella, es cierto que existen formas artísticas de representar el cuerpo pero son imágenes, sin embargo de alguna manera se da razón del cuerpo, se expresa, busca y encuentra un lugar en el universo, de tal manera que las estructuras de comunicación oral implican un cierto orden corporal.

Ante la insuficiencia de esta episteme oral da inicio el surgimiento de la escritura la cual es una actividad humana relativamente nueva con respecto a las formas de comunicación oral, en sus inicios la escritura es pictográfica, la palabra se transforma en objetos materiales representados por medio de dibujos, los fonemas no tienen aún una representación gráfica, de tal manera que la escritura nace separada de la palabra y poco a poco logran su comunión.

El significado de escribir tiene que ver con ranurar, dejar marca, rasgar, etc. de tal manera que por ejemplo, el inglés "Write" y el alemán "Ritzen" aluden a rascar y el inglés antiguo "runa" significa arar; en términos generales, la escritura implica una acción al exterior del cuerpo sobre algo y es realizada con algún instrumento para fijar una marca. Las primeras actividades humanas que tuvieron la necesidad de hacer esto fueron los cálculos numéricos y los sellos de grabado, ambas actividades para señalar la propiedad de algo, contraria a la forma de comunicación oral en la cual no era necesario instrumento alguno para transmitir ideas, la escritura requería de ciertos instrumentos para grabar.

La escritura al permitir que el cuerpo se comunicara y dejara huella de él se convierte en la téchne corporal porque más allá de ser un instrumento importante para la creación de la historia del cuerpo mismo, propició el desarrollo de toda una forma de interpretar y dar razón del universo, surge y se consolida como la episteme predominante desde la cual 
el hombre crea su universo simbólico que dió respuesta a la insuficiente racionalidad oral anterior a la escritura.

En este proceso el papel de los instrumentos tecnológicos fue y es fundamental, pudiera decirse que fue la tecnología el catalizador que precipitó la potencialidad del lenguaje oral para ser representado de manera simbólica "Al principio los signos se dibujaban sobre la superficie de arcilla apenas húmeda con un instrumento puntiagudo, pero pronto se adoptó la técnica de imprimir la silueta del signo en la arcilla con un fino estilo de junco. Este último método dio a la escritura cuneiforme su característica apariencia de cuñas e inició el proceso de reducción de los símbolos originales a combinaciones de líneas convencionales." (GREEN, 1992, p. 48).

La escritura pictográfica transitó a la ideográfica y de allí a la cuneiforme, en los tres casos los instrumentos tecnológicos desempeñaron un papel fundamental haciendo incluso de la escritura un arte, como se indica al inicio de este trabajo, arte y téchne surgen de manera simultánea, son actividades complementarias de la racionalidad tecnológica, de tal manera para que el cuerpo nuevo aprendiera a expresarse de forma escrita fue necesario crear ciertos artefactos tecnológicos y aprender a utilizarlos (lo cual implicaba el arte de pintar signos) este proceso originó una adecuación representacional de nuestro cuerpo.

Los primeros pictogramas e ideogramas fueron representaciones simbólicas del cuerpo humano y de las imágenes de las cosas de las que daba razón, que al evolucionar en sus formas representacionales darían origen a los símbolos base de los actuales alfabetos como se muestra en la siguiente ilustración.

La escritura pictográfica tenía demasiados signos por lo que era difícil de aprender, y resultó ser privativa de ciertos sujetos que la dominaban (por ejemplo artistas, sacerdotes, burócratas y administradores), surge así la escritura cuneiforme, la cual representó, por medio de símbolos grabados en forma de cuñas, a la gran cantidad de dibujos necesarios para escribir con pictogramas, este tipo de escritura hizo llegar a clases menos privilegiadas la posibilidad de aprenderla, la invención de esta escritura se produjo en el marco de la rápida expansión del ambiente urbano, la estratificación social y la especialización tecnológica de las culturas que 
adoptaron esta forma de escribir; posteriormente este tipo de escritura dejó su lugar a las escrituras alfabéticas y los medios de pincel y tinta que consolidaron a esta última como la forma dominante de escribir y en consecuencia, de leer.

La invención del alfabeto representó muchas ventajas para consolidar a la escritura por encima de cualquier otra forma de comunicación, redujo la gran cantidad de símbolos requeridos para aprender a escribir (los diversos alfabetos que surgieron tenían entre 20 hasta 30 letras), lo cual implicó menor dificultad para su aprendizaje y estar más a la mano del ciudadano común, el arte y la cultura dejaron, en cierta medida, de ser un privilegio; el cuerpo humano consolida su individualidad participando de una actividad común como es la escritura alfabética, que al asignar una consonante para cada símbolo pictográfico le da al hombre la ancha posibilidad de crear diferentes combinaciones y cadenas de tales símbolos para escribir lo que se dice, de esta manera nuestro cuerpo alfabético se inserta en un orden del cual él mismo es creador.

El cuerpo humano no es sólo inmanencia, es una potencialidad, movimiento y posibilidad de autoconstrucción en armonía con su medio ambiente que es su lugar, su espacio, pero no en un sentido pasivo, como de mera inserción, sino como elemento de su propia autoconstrucción y en consecuencia, de su transformación.

El cuerpo inmanente no es un cuerpo humano propiamente dicho, el cuerpo humano es exterior, se extiende, se va expandiendo con y en su entorno para lo cual se transforma en símbolos, es el cuerpo el símbolo más representado en diferentes obras de arte, de esta manera el cuerpo se representa a sí mismo, se autorretrata para verse y dar razón de sí, más aún, utiliza partes de su propia estructura para crear signos que le permitan expresarse, lo cual deviene en la escritura, es un ente que para dar razón de sí utiliza sus propios componentes.

\section{Implicaciones de la escritura en tanto téchne del cuerpo}

El cuerpo humano deja sus huellas para decir algo, es lo único cuerpo en el universo que hace esto, se recrea a sí mismo pero no como una copia fiel, más bien es un cuerpo inconforme con lo que es, se recrea y expresa 


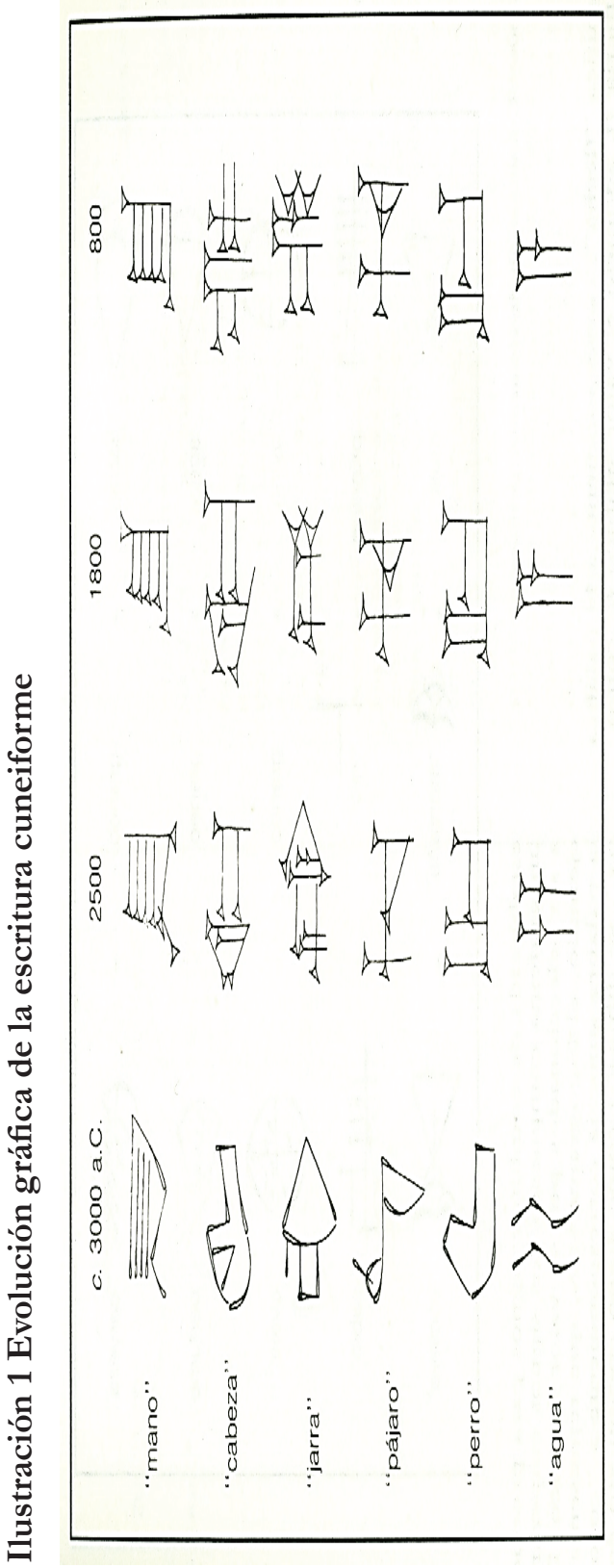

EdUCAÇÃO \& LINGUAGEM • V. 21 • N. 1 • 131-148 • JAN.-JUN. 2018 
con sus propios componentes, no le vasta la imagen de sí que le devuelve el espejo, porque aún siendo exacta es fría, no es suficiente la imagen pintada, ni lo volátil de la palabra; prefiere la posibilidad de la escritura porque le permite describirse de diversas maneras y situaciones, incluso puede viajar en una carta, en un poema, en una novela, etc. La escritura es la huella del cuerpo posible, su expansión y diversificación; para que el cuerpo humano sea tal debe poseer exterioridad, extensión y exposición, para existir hay que ser exterior lo cual es condición del sí mismo humano "El ser sí mismo es necesariamente ser fuera, en el afuera, ser expuesto o extenso. Es lo que Heidegger intenta hacer decir a la palabra Daisen (la existencia)" (NANCY, 2003, p. 106) y esa exteriorización en potencia es detonada por la escritura en tanto téchne, la escritura como téchne del cuerpo humano le permite esa existencia al hacerlo exterior, extenderlo y exponerlo; podemos decir que la escritura le permite al cuerpo ex-cribirse, somos un universo ins-crito que se ex-cribe indicándonos que con-formamos al universo mismo y ese proceso de ex-critura es nuestra téchne alfabética.

Nuestro cuerpo se extiende, expande y expone para tocarse a sí mismo; para sentirse, y la escritura propicia ese tocamiento del cuerpo, porque se escribe para otros cuerpos, para ponerse en contacto con otros, escribir permite tocar, tocando a los demás, pudiera decirse que escribir es un sentido más de la estructura corporal, una especie de tacto a distancia, que le permite al hombre exteriorizarse para ser percibido por los otros y así tocar a los que están distanciados, es así que lo reconocimiento y tocamiento del cuerpo viene del exterior, en este sentido la escritura es la téchne del cuerpo por excelencia que permite ese tacto exterior y a distancia, que propicia en el cuerpo creación y recreación de sí mismo, en este sentido la escritura no es otro cuerpo, sino es el cuerpo mismo que se exterioriza representándose a sí mismo.

\section{Transformación de la téchne y sus implicaciones pedagógicas (a manera de reflexiones finales)}

La idea animista de lo que son tanto la tecnología como la escritura ha tenido implicaciones educativas y pedagógicas determinantes sobre todo en las actuales sociedades posmodernas, somos sociedades escrituro-céntricas, y como tales, gran parte de nuestra actividad cultural gira en 
torno a la escritura, sin embargo la etapa actual del posmodernismo ha marcado, entre otros cambios, el de la escritura sobre todo en relación a la tecnología que implica el soporte sobre lo cual se escribe, en este sentido la actual tecnología digital ha trastocado a la escritura y nuestras formas de comunicarnos a través de los procesos de escritura digital.

La tecnología atómica y nuclear, aúnque también representaron en su momento un cambio de amplio espectro, éste no fue de la misma magnitud como el actual porque este tipo de tecnología transformó otros ámbitos de la cultura (p. ej. el productivo y el energético principalmente), no generaron una revolución como la que hoy presenciamos con el advenimiento de las tecnologías digitales.

La escritura en tanto téchne del cuerpo implica, una relación de mutua interestructuración en la cual los cambios y evoluciones impactan en las partes del todo involucradas en el proceso de la escritura, esto es importante porque la actual estructura tecnológica digital ha impactado de manera directa en la forma de escritura, en el surgimiento y creación de nuevos símbolos, lenguajes y reglas gramaticales transformando a la escritura alfabética-libresca en digital-hipertextual-virtual.

La escritura alfabética representó la consolidación de los logos verbales posibilitando la representación de la palabra y en consecuencia, el surgimiento de ciertas formas de razonamiento así como de nuevas maneras de educar, el nacimiento de la imprenta significó la consolidación del hombre librepensador con un raciocinio diferente y una educación distinta a la que se venía teniendo antes del renacimiento; el surgimiento de un cuerpo moderno con formas de representación diferentes así como la posibilidad de educarse de otra manera y en otro espacio alternativo al hogar (espacio escolar); la téchne rupestre, la alfabética, la surgida de la imprenta y actualmente la digital implican profundos cambios en las formas de representación del cuerpo humano, de las formas de razonamiento y de educación.

El cuerpo de hoy ya no tiene que rasgar en la arcilla para expresarse ni utilizar partes de sí mismo para crear símbolos de representación, el hombre de hoy ha ido más lejos y ha sido capaz de crear un espacio virtual al representar de manera digital su realidad (incluido él mismo), en 
ese espacio virtual se pueden crear y representar cosas que permanecen y fluyen entre los usuarios.

El cuerpo deja de ser escrituro-céntrico para transformarse en fluido permanente, factible de ser manipulado por los usuarios, si bien la escritura alfabética-libresca "escrituró" al cuerpo, lo arraigó a un territorio; hoy la escritura digital-virtual lo transforma en fluido, es un cuerpo portátil que crea mundos itinerantes virtualizando de manera digital la realidad. Esta nueva forma digital de escribir representa de alguna manera una forma de neoliberalismo y globalización de nuestro cuerpo al permitirle formas alternativas de expresarse, como en su momento la escritura y la imprenta significaron el surgimiento de un cuerpo nuevo, alternativo, más libre. "Tú en la red puedes estar en muchos espacios al mismo tiempo, en el mismo instante cambiar, irte a la Universidad o estar con otra persona, al mismo tiempo, [...] puedo estar conectado con varias personas y con temas distintos con cada uno, son espacios pequeños, tú estás metido entre ellos, te sales y te metes permanentemente. [...]" (MARTÍNEZ OJEDA, 2006, p. 57).

La sociedad contemporánea se caracteriza por estar conformada de flujos (de información, de capital, etc.) nuestra estructura corporal puede ser representada mediante imágenes de síntesis y a partir de ello adquirir una estructura de flujo capaz de crear sus propios espacios para desplazarse en ellos creando así formas alternativas de convivencia con todo lo que ello implica, es decir, con éticas, políticas y formas de comunicación emergentes lo cual tiene implicaciones educativas y pedagógicas (entre otras) interesantes de analizar y que rebasan este espacio para ello; lo arraigo territorial del cuerpo consolidado por la escritura y la educación escolar se ha trasformado, fenómeno propiciado en gran medida por el surgimiento de la nueva téchne digital, la cual le permite al cuerpo adquirir una apariencia virtual digital y actuar como si se encontrara en espacios públicos reales, pero en realidad son narraciones electrónicas habitadas por cuerpos descritos a partir de una forma diferente de ser escritos, por lo que se adquieren nuevas experiencias comunicativas, sensoriales y educativas ni más, ni menos buenas, desconocidas sí, pero funcionales en la vida cotidiana, fuera de los ámbitos formalmente instituidos (sobre todo los formalmente educativos). 
El cuerpo de la téchne digital es más visual, más lúdico, utiliza herramientas digitales para explorar el mundo de otras formas y aúnque algunos autores afirman que queda excluido en los procesos de comunicación debido a la no presencia física, yo más bien apuntaría que crea formas alternativas de mediación (incluyendo la mediación pedagógica).

Finalmente es importante apuntar que el cuerpo humano no es pasivo ni víctima, el cuerpo humano es movimiento y cambio, siempre lo ha sido, ¿por qué ahora debería ser pasivo?, el cuerpo humano continua expandiéndose, complementándose y transformándose, proceso en lo cual la escritura, en tanto téchne, juega un papel importante; la pasividad puede venir de nuestra forma de ver las cosas, de las formas de querer educar a los sujetos actuales y no reconocer sus potencialidades emergentes que les permite aprender y comunicarse de maneras alternativas a las nuestras, es importante que desde la pedagogía aprendamos a ser más sensibles y atentos al surgimiento de estas formas alternativas y construir los referentes teórico metodológicos de interpretación adecuados y no solamente interpretar la dinámica emergente a partir de nuestras estructuras de entendimiento sin hacer caso a aquello que queda fuera de nuestros ángulos de lectura para descalificarlo, muy probablemente en eso que descalificamos se encuentre la esencia de lo que está cambiando.

\section{Referencias}

CRAGNOLINI, Mónica Beatriz. Del cuerpo-escritura. Nietzsche, su "yo" y sus escritos. 2000. Disponível em: <http://www.nietzscheana.com.ar/comentarios/cuerpo-escritura.htm>. Acesso em: 13 jan. 2018.

FOUCAULT, Michel. Las palabras y las cosas. México: Siglo XXI, 2007.

GREEN, Margaret. La escritura cuneiforme temprana. In: SENNER, Wayne (Comp.). Los orígenes de la escritura. México: Siglo XXI, 1992. p. 47-60.

MARÍN ARDILA, Luis Fernando. Técnica y virtualidad. Pensar las nuevas tecnologías. Cuaderno de materiales Filosofía y ciencias humanas, n. 18, 2002. Disponível em: <http://www.filosofia.net/materiales/num/num18/Tecnivir. htm>. Acesso em: 13 jan. 2018. 
MARTÍNEZ OJEDA, Betty. Homo digitalis: etnografía de la cibercultura, Bogotá: Ediciones Uniandes, 2006. Disponível em: <http://faciso.uniandes.edu. com>. Acesso em: 13 jan. 2018.

MITCHAM, Carl. ¿Qué es la filosofía de la tecnología?. Barcelona: Anthropos, 1989.

NANCY, Jean-Luc. Corpus. Madrid: Arena Libros, 2003.

ONG, Walter Jackson. Oralidad y escritura. Tecnologías de la palabra. México: Fondo de Cultura Económica, 1987.

ORTEGA Y GASSET, José. Meditación de la técnica. Madrid: Espasa-calpe, 1965.

Submetido em: 8-5-2018

Aceito em: 22-5-2018 